\title{
CREATION OF A VIRTUAL REALITY ENVIRONMENT OF A UNIVERSITY MUSEUM USING 3D PHOTOGRAMMETRIC MODELS
}

\author{
K. P. Martinez ${ }^{1}$, M. Z. G. Untalan ${ }^{1}$, D. F. M. $\operatorname{Burgos}^{1}$, R. V. Ramos ${ }^{1, *}$, M. J. Q. Germentil ${ }^{1}$ \\ Department of Geodetic Engineering, University of the Philippines Diliman - \\ (dmburgos, kpmartinez1, rvramos, mqgermentil, mguntalan)@up.edu.ph
}

KEY WORDS: Virtual Reality, University Museum, 3D Models, Photogrammetry, Low-cost, Structure-from-Motion, Indoor

\begin{abstract}
:
Museums and exhibits are conventionally experienced first-hand through physical interaction with the display and features. Afar from these museums, photographs and videos provide a way to view these museums, but this is an experience far from the actual physical interaction. We study in this research how 3D modelling and photogrammetry can be used to create a virtual reality (VR) environment of a university museum named Bulwagan ng Dangal in the University of the Philippines-Diliman. The main software used were 3DF Zephyr for photogrammetric modelling and AutoDesk Maya for 3D modelling of the VR environment. Models were created based of photographs taken using a DSLR camera and mobile phones. Model validation results show 2.42 $\%$ to $7.00 \%$ errors. The study suggests that photogrammetric methods can be used to create a VR environment of museums or similar indoor exhibits for the purpose of experience and effective visualization.
\end{abstract}

\section{INTRODUCTION}

\subsection{Background}

Modern advancements in technology paved way to 3D modeling using photogrammetric methods, particularly using only two-dimensional (2D) photographs to create realistic 3D structures by an automated software process. The resulting 3D models can be used in various applications such as architectural visualization, urban modelling, and recording of cultural heritage to name a few (Hellman et. al., 2018). One new application of $3 \mathrm{D}$ models is in virtual reality (VR) environment creation. VR refers to a $3 \mathrm{D}$, computer-generated environment where users can interact with the objects in this kind of setting and immerse themselves through platforms that support virtual reality. VR environments must be carefully engineered for a more convincing experience. A convincing VR must exude a level of immersion. (Virtual Reality Society, n.d.). Most people are familiar with VR as related to gaming technologies. However, VR environments can also be used in relation to cultural heritage conservation and management.

The usual mode in museums and historical settings involves passive engagement wherein people only get to view and not interact with the main feature. VR can be used in museum and historical settings as means of interaction to communicate information to the general public in new and exciting ways. According to a study, the effect of VR can be analyzed through three motives - social, progressive, and immersive. Social motives are characterized by a desire to communicate and interact with real people; progressive motives are aimed at character development; immersive motives are characterized by the desire to learn new things. These three motives drive users to use VR and encourage them to achieve these in real life (Science Cinema VR, 2018). Thus, through
VR, the notion of having boring experience when visiting heritage sites could be minimized and heritage sites could open up to new and much broader audiences.

The recent advancements in computer vision and photogrammetry has made 3D modeling of cultural heritage common for documentation and visualization (Soler et. al., 2017). In the recent years museums and cultural heritage have been documented using SfM software with satisfactory results (Inzerillo, 2017).

\subsection{Objectives}

Conventional methods of documentation and remote presentation of exhibits include photographs and video recordings which provide viewing access, but immersion and experience is limited. In this study we explore the value of photogrammetry and $3 \mathrm{D}$ modelling to produce a VR environment in accompanying and/or replacing conventional methods. The study explores if the created virtual reality environment of a university museum can augment the user interaction from just viewing, in the case of photos and video, to experience a certain degree of immersion.

\subsection{Significance}

With the advent of immersive technologies, it is a step forward for geospatial visualization and GIS to incorporate augmented experience and immersion into spaces such as indoors. The study combines the superior visualization attribute of photogrammetric 3D models over still photos, the versatility of a VR environment over recorded videos, and immersive capability of a VR environment, currently fashionable in gaming, to present a university museum in a digital form which delivers a good experience to viewers even when physical interaction is absent. The study shows that VR 
technology is an additional way of documentation. Furthermore, the study shows that VR technology that is currently popular for games because of its immersion can be used in conjunction with photogrammetry to provide an immersive / semi-immersive experience, depending on purpose, of an indoor environment like a museum.

\subsection{Study Area}

The study area is the Bulwagan ng Dangal. It is the largest exhibition hall in the University of the Philippines Diliman, Quezon City, Philippines and is located at the basement of Gonzalez Hall. An exhibition housed in Bulwagan ng Dangal is the subject of the VR environment generated.

The exhibition was titled 'Stasis and Mobility: Nasa Dugo Natin 'Yan?!'. It was an exhibit on Philippine genetics and culture that ran from 19 October 2018 to 16 November 2018. The exhibition was divided into four galleries - science, language, heritage, and citizenship. The Science Gallery presented visual artworks (paintings and a helix DNA installation) about genetics. The Language Gallery utilized a large LED screen that played a narrated animation about the Philippines' Austronesian ancestors. The Heritage Gallery showcased the rice culture of the Dumagat, Iraynon-Bukidnon, and Kalanguya and Tuwali through three wooden installations that mimicked the double-helix structure of DNA. The Citizenship Gallery was about the narratives of Filipino genes using an installation art that used photos and nylon string to portray a boat-like structure.

\subsection{Scope and Limitation}

The study did not include the Language and Citizenship Gallery in the VR environment. The Language Gallery used a narrated animation on an LCD screen which cannot be represented in one still photograph. The Citizenship Gallery was not included because it showcased a plethora of strings attached from the ceilings to the floors with free-hanging photographs attached. This exhibit was featured with a black backdrop. With the complexity of the exhibit, together with the fact that this was done in an uncontrolled environment, this exhibit was opted out in modelling / photogrammetry.

\section{METHODOLOGY}

\subsection{Data and Materials}

A DSLR camera was used for capturing images used for photogrammetric modelling and a smartphone camera was used for capturing images used for 3D modelling like in the case of textures and colors. The specifics are shown in Table 1. A circular polarizing (CPL) filter was used to minimize reflections.

\begin{tabular}{|c|c|c|}
\hline $\begin{array}{c}\text { Camera } \\
\text { Specification }\end{array}$ & $\begin{array}{c}\text { Canon 600D with } \\
\text { 18-55mm Lens } \\
\text { (DSLR) }\end{array}$ & $\begin{array}{c}\text { Samsung } \\
\text { Galaxy S9+ } \\
\text { (Smartphone) }\end{array}$ \\
\hline Camera Type & Digital Single- & Mobile \\
\hline
\end{tabular}

\begin{tabular}{|c|c|c|}
\hline & $\begin{array}{l}\text { Lens Reflex } \\
\text { Camera }\end{array}$ & Camera \\
\hline Sensor Type & $\begin{array}{c}\text { Complementary } \\
\text { Metal-Oxide } \\
\text { Sensor } \\
\text { (CMOS) (APS-C } \\
14 \\
\text { x } 22.3 \mathrm{~mm})\end{array}$ & $\begin{array}{l}\text { S5K2L3 } \\
\text { ISOCELL }\end{array}$ \\
\hline Resolution & $18 \mathrm{MP}$ & $12 \mathrm{MP}$ \\
\hline Image Stabilizer & Optical & Optical \\
\hline Focal Length & $18-55 \mathrm{~mm}$ & $4.6 \mathrm{~mm}$ and $6 \mathrm{~mm}$ \\
\hline Aperture Range & $\mathrm{f} / 3.5$ to $\mathrm{f} / 25$ & $\mathrm{f} / 1.5$ and $\mathrm{f} / 2.4$ \\
\hline ISO Range & $\begin{array}{l}\text { Auto mode, from } \\
100 \text { to } 6400 \text { ISO }\end{array}$ & $\begin{array}{c}\text { Auto mode, } \\
\text { from } 100 \text { to } \\
800\end{array}$ \\
\hline $\begin{array}{c}\text { Shutter Speed } \\
\text { Range }\end{array}$ & $\begin{array}{l}\text { from } 1 / 4000 \text { (of a } \\
\text { second) to } 30 \mathrm{~s}\end{array}$ & $\begin{array}{l}\text { From } 1 / 2500 \\
\text { (of a second) } \\
\text { to } 10 \mathrm{~s}\end{array}$ \\
\hline
\end{tabular}

Table 1. Specification of the cameras used in the study

The computers used in this study for the generation of the textured 3D photogrammetric models and creation of VR environment were OptoFrame W-500 and MSI GS70 2QE, respectively. Table 2 shows the specifications.

\begin{tabular}{|c|c|c|}
\hline Specification & $\begin{array}{c}\text { MSI GS70 2QE } \\
\text { Stealth Pro }\end{array}$ & $\begin{array}{c}\text { OptoFrame } \\
\text { W-500 }\end{array}$ \\
\hline Processor & $\begin{array}{c}\text { Intel Core i7- } \\
\text { 4710HQ } \\
\text { processor }\end{array}$ & $\begin{array}{c}\text { Intel(R) } \\
\text { Xenon(R) } \\
\text { CPU ES - } \\
2620 \mathrm{v} 2 \\
(2 \text { processor })\end{array}$ \\
\hline $\begin{array}{c}\text { Graphics } \\
\text { Processing Unit }\end{array}$ & $\begin{array}{c}\text { NVIDIA } \\
\text { GeForce GTX } \\
970 \mathrm{M}\end{array}$ & None \\
\hline RAM & $16 \mathrm{~GB}$ & $32 \mathrm{~GB}$ \\
\hline
\end{tabular}

Table 2. Specifications of the computers used for the creation of the VR environment and for image processing

\subsection{Reconnaissance and Permission}

A reconnaissance survey is the basis for choice of parameters for camera calibration and the approach for acquisition. This also included asking permission from the head curator which was immediately approved.

\subsection{Image Acquisition}


According to the study of Lahti et. al. (2018), there are some rules to follow in gathering digital images for $3 \mathrm{D}$ modelling. This includes considering the high amount of overlaps between photos for continuity, and not using the automatic settings and built-in flash of the camera to have uniform brightness of the images. The shooting distances and the focus of the camera should also be consistent throughout the image acquisition. Highly reflective surfaces and transparent or translucent objects should be avoided as much as possible because the 3D modelling software distinguish them as moving objects (Lahti et.al., 2018).

During this phase, several photographs will be taken as planned based on the reconnaissance survey. In this case, a semi-systematic approach was used. Measurements were done on certain dimensions of measurable features such as width of paintings, floor tile dimension, and the like.

\subsection{D Textured Model Generation using 3DF Zephyr}

3DF Zephyr is a commercial photogrammetry and 3D modelling software that was developed and marketed by the Italian software house 3DFLOW (3DFlow, n.d.). Image processing tasks using 3DF Zephyr include selection and removal of faulty photos, camera orientation and image matching.

\subsection{Creation Virtual Reality Environment}

AutoDesk Maya is a 3D computer graphics application originally developed by Alias Systems Corporation but are not currently marketed by Autodesk, Inc. (Autodesk, n.d.). The software is utilized for the generation of the VR environment of the exhibition.

Surfaces that were highly reflective like floors, pillar, and walls are expected to be rendered deformed because of the reflections despite using a CPL filter. The textured photogrammetric models were used together with the 3D modelled features to produce a VR environment using AutoDesk Maya.

\subsection{VR Environment Validation and Accuracy Assessment}

The different measurements of various objects and fixtures in the museum, such as the dimensions of paintings, tiles, and walls were compared with the produced textured model to assess the accuracy of the modelled environment. Since the digital model was scaled to save space and speed up processing, scaling was correspondingly done in comparing the real world measurements with the digital measurements. The scale factor is computed using the following equation.

$$
\text { scale factor }=\frac{\text { photo distance }}{\text { ground distance }}
$$

The scaled measurements and ground measurements were compared to determine the percent deviation of the measurements from the textured $3 \mathrm{D}$ model. The root mean square error is also reported.

\subsection{Comparison with Traditional still Photographs and Panoramic Images}

A survey was conducted where participants were asked several questions regarding the efficacy of the virtual reality environment as compared to photographs and panoramas.

The participants were asked of basic information, with their name being optional. The participants were asked to rate the several statements from 1 to 5,1 being strongly disagree, 2 being disagree, 3 being neutral, 4 being agree, and 5 being strongly disagree.

The statements were to explore the possible uses of VR. The statements were about the visual accuracy of the model, the capability of it to replace photographs, capability of generalizing other indoor places, provision of an semi/fully immersive experience, and the utility of it for visualization.

Lastly, the participants were asked (yes or no) if they prefer the virtual reality environment over panoramic images and if they think that a VR environment can be a great alternative to experience going to museums/exhibits that are inaccessible to them.

\section{RESULTS AND DISCUSSION}

\subsection{Camera Parameters and Acquisition Approach}

Several notable information were gathered during the reconnaissance survey which included people walking around exhibits that should not be present in the photographs, highly reflective surfaces in the museum, and the yellowish tint due to the lights used in the museum. A semi-systematic approach was used because the museum was an uncontrolled environment. A CPL filter was used to reduce reflections. The following DSLR camera parameters (Table 3) were used throughout the process.

\begin{tabular}{|c|c|}
\hline Parameter & Setting \\
\hline Focal Length & $18 \mathrm{~mm}$ \\
\hline Aperture & $\mathrm{f} / 11$ \\
\hline Shutter Speed & $1 / 5$ (of a second) \\
\hline ISO & 6400 \\
\hline White Balance & Fluorescent \\
\hline Focusing & Manual Focus \\
\hline Metering & Point Metering \\
\hline Distance from the object & $1 \mathrm{~m}$ to $8 \mathrm{~m}$ \\
\hline
\end{tabular}

Table 3. DSLR camera used throughout acquisition

3.2 Image Acquisition and Photogrammetric Modelling 
The semi-systematic approach proved to be excellent because it allowed the acquisition of images to avoid capturing people in the photographs. The image below shows the oriented cameras on a top view of the museum. The camera was also freely adjusted in position to avoid reflections and glares.

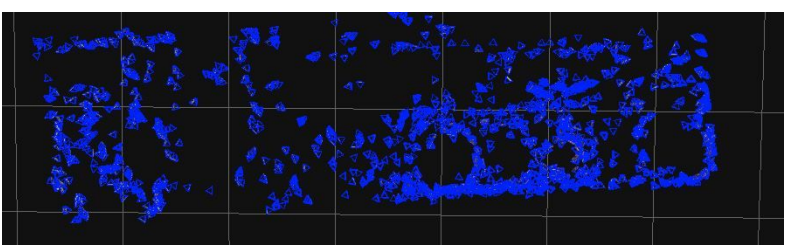

Figure 1. Oriented cameras viewed overhead

Since there were a huge number of images, the photogrammetric modelling took about 100 hours in total or approximately 4 days. The breakdown of this is shown in Table 4

\begin{tabular}{|c|c|}
\hline Processing Stage & Duration (hours) \\
\hline Image Matching & 38 \\
\hline Sparse Cloud & 18 \\
\hline Dense Cloud & 20 \\
\hline Mesh & 15 \\
\hline Textured Mesh & 9 \\
\hline
\end{tabular}

Table 4. Processing time per stage

The CPL filter was helpful in reducing the reflections on the floors, pillars, walls, glass coverings of paintings, and the like, but there were still reflections that resulted in distorted or poorly reconstructed portions of the textured model. Nevertheless, objects and exhibits were still well represented.

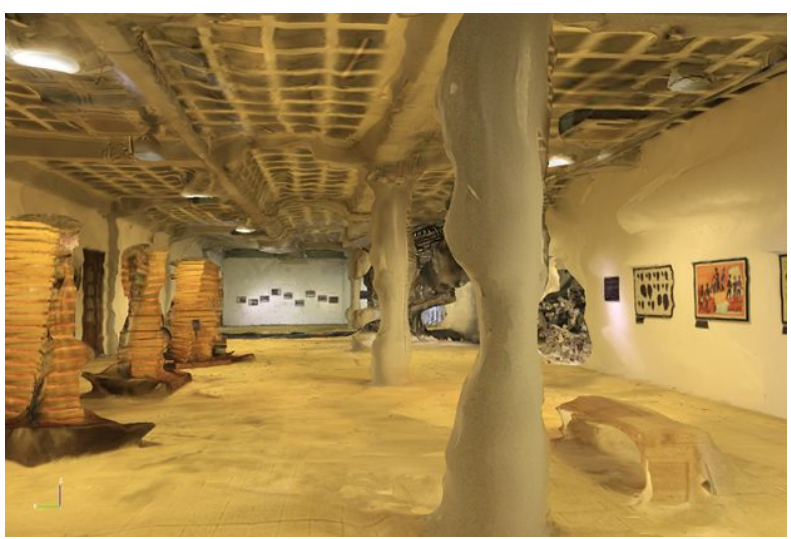

Figure 2. A view along the long axis of the textured model

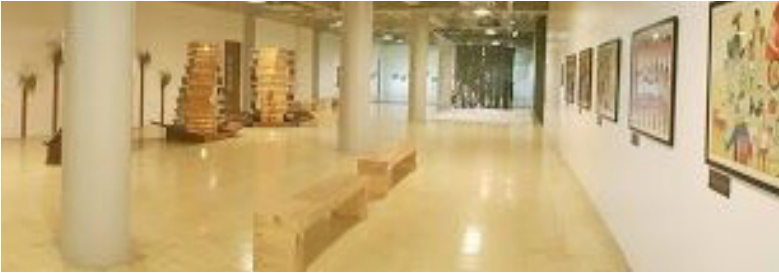

Figure 3. A photograph in a similar view for comparison

A total of five sessions were conducted which was strategically scheduled to avoid many people in the museum during capture. There were total of about 3000 images used in the generation of a textured model. Table 5 shows the outcomes and remarks for each session.

\begin{tabular}{|c|c|}
\hline Session & Remark \\
\hline 1 & $\begin{array}{c}\text { About 3/4 of the museum were covered by } \\
\text { overlapping photos of different perspectives } \\
\text { and angles }\end{array}$ \\
\hline 2 & $\begin{array}{c}\text { Focused on individual objects of the exhibits } \\
\text { while still capturing a portion of the museum } \\
\text { in the background of the picture for tie points }\end{array}$ \\
\hline 3 & $\begin{array}{c}\text { Took photographs to overlap with the } \\
\text { previous sessions }\end{array}$ \\
\hline 4 & $\begin{array}{c}\text { Focused on the portion of the museum which } \\
\text { was farthest from the entrance which } \\
\text { contained several paints hung on the wall }\end{array}$ \\
\hline 5 & Same with Session 4 \\
\hline
\end{tabular}

Table 5. Remarks on sessions of image acquisition

\subsection{D Modelling}

To compensate for the deficiencies of the photogrammetric model, such as deformed walls, floors, and pillars, 3D models of these were done in AutoDesk Maya. The textures and colors were derived from photographs as well, this time, from the pictures taken using the smartphone camera.

The photogrammetric models and the 3D models were then combined in AutoDesk Maya to finish and polish the VR environment for the museum. Several subtle details were added such as lights. The VR environment is shown below. 


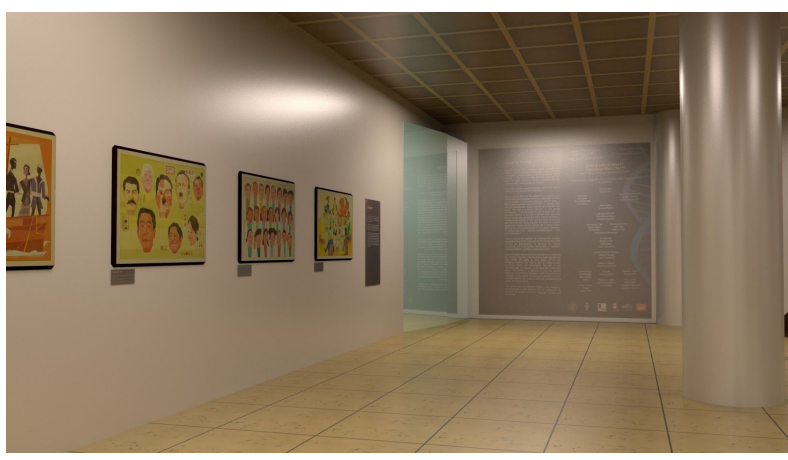

Figure 4. VR Environment near the entrance

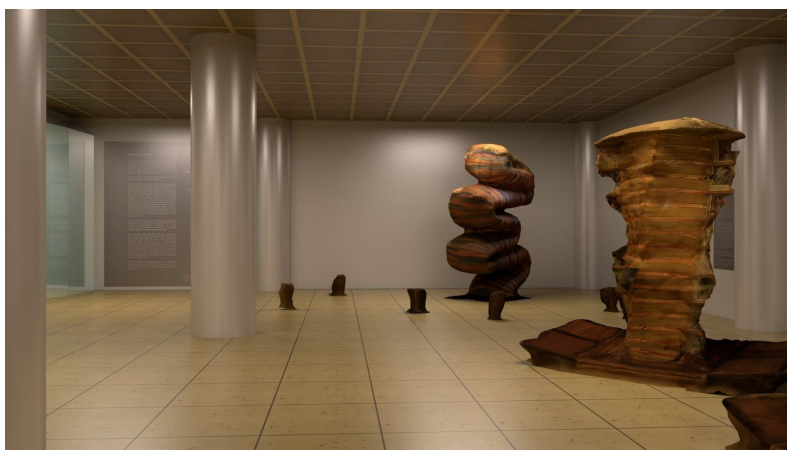

Figure 5. VR Environment showing exhibits

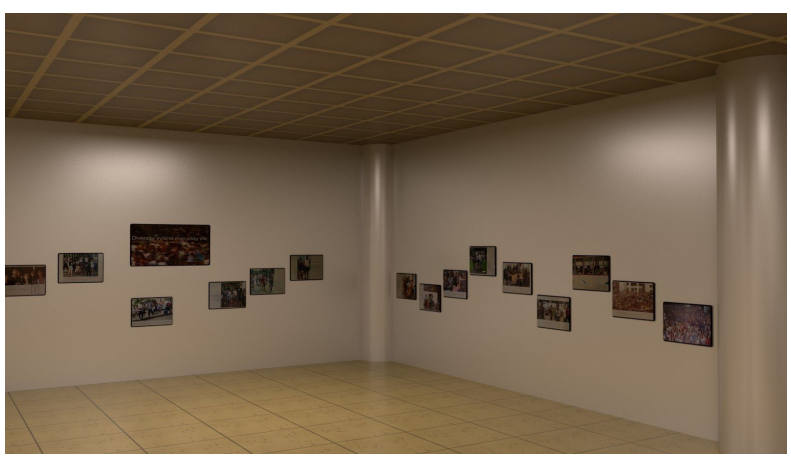

Figure 6. VR Environment showing the far end

\subsection{Assessment of Measurements Done}

The measurements done in the museum are compared with the measurements done in the photogrammetric model, with the appropriate scaling. Table 6 shows the comparison with the measurements on the model already scaled.

\begin{tabular}{|c|c|c|c|c|}
\hline $\begin{array}{c}\text { Observa- } \\
\text { tion }\end{array}$ & $\begin{array}{c}\text { Ground } \\
\text { Measure- } \\
\text { ment (m) }\end{array}$ & $\begin{array}{c}\text { Model } \\
\text { Measure- } \\
\text { ment (m) }\end{array}$ & $\begin{array}{c}\text { Absolute } \\
\text { Devia- } \\
\text { tion (m) }\end{array}$ & $\begin{array}{c}\text { Percent } \\
\text { Devia- } \\
\text { tion (\%) }\end{array}$ \\
\hline 1 & 0.607 & 0.578 & 0.029 & 4.78 \\
\hline 2 & 1.183 & 1.142 & 0.041 & 3.47 \\
\hline 3 & 0.828 & 0.808 & 0.020 & 2.42 \\
\hline
\end{tabular}

\begin{tabular}{|c|c|c|c|c|}
\hline 4 & 0.200 & 0.188 & 0.012 & 6.00 \\
\hline 5 & 0.200 & 0.186 & 0.014 & 7.00 \\
\hline
\end{tabular}

Table 6. Comparison of ground and model measurements

The table shows a minimum of $2.42 \%$ deviation and a maximum of $7 \%$ deviation. The root mean square error is $5.7 \mathrm{~cm}$. This shows good accuracy for the photogrammetric model.

\subsection{Comparison with Photographs and Panoramic Images}

There were five statements to be rated from 1 to 5 corresponding to strongly disagree to strongly agree. There were two yes or no questions. The survey has received 30 participants. The answers are summarized in Table 7.

\begin{tabular}{|c|c|c|c|c|}
\hline Quality & $\begin{array}{c}\% \\
\text { Positive }\end{array}$ & $\begin{array}{c}\% \\
\text { Neutral }\end{array}$ & $\begin{array}{c}\% \\
\text { Negative }\end{array}$ & Mode \\
\hline $\begin{array}{c}\text { Visual } \\
\text { Accuracy }\end{array}$ & 70 & 23.3 & 6.7 & 4 \\
\hline $\begin{array}{c}\text { VRE as } \\
\text { alternative to } \\
\text { photos }\end{array}$ & 73.3 & 16.7 & 10.0 & 4 \\
\hline $\begin{array}{c}\text { Documentatio } \\
\text { n quality }\end{array}$ & 90.0 & 10.0 & 0.0 & 4 \\
\hline $\begin{array}{c}\text { Immersive } \\
\text { quality }\end{array}$ & 80.0 & 13.3 & 6.7 & 4 \\
\hline $\begin{array}{c}\text { Realistic } \\
\text { visualization }\end{array}$ & 66.7 & 26.7 & 6.7 & 4 \\
\hline
\end{tabular}

Table 7. Summary of ratings in survey

\begin{tabular}{|c|c|c|}
\hline Yes/No Question & \% Yes & $\%$ No \\
\hline $\begin{array}{c}\text { Preference over } \\
\text { Panorama }\end{array}$ & 86.7 & 13.3 \\
\hline $\begin{array}{c}\text { Great alternative to } \\
\text { experience going to } \\
\text { museums/exhibits that } \\
\text { are inaccessible }\end{array}$ & 86.7 & 13.3 \\
\hline
\end{tabular}

Table 7. Summary to yes or no questions

The most frequent answer for all of the rating of statements was 4 which corresponds to agree. There were a small percent of negative answers for all rating of statements which can be attributed to the errors or imperfections due to the deficiencies of the equipment / method and the uncontrollability of the environment. For example, the visual accuracy could be improved if a laser scanner was used. In the case of realistic visualization, better artistry in $3 \mathrm{D}$ modelling would lead to better results. Overall, better equipment and better artistry 
would lead to the general improvement of the virtual reality environment.

Nevertheless, a large portion of the number of participants would prefer VR over panorama and as alternative to physical experience in the case of inaccessibility. The virtual reality environment is, therefore, a viable product for visualization, documentation, immersive experience, alternative to physical experience, among others.

\subsection{Extension of Applicability to Other Indoor Environments}

The university museum targeted for this study has qualities of different indoor environments such as, uneven lighting, harsh lighting in some areas, reflective surfaces, and the like. Because of these shared qualities with other indoor environments, the results and findings due to the virtual reality environment made for the Bulwagan ng Dangal Museum can be extended to other indoor environments. It is worthy to mention that only similar environments will yield similar results - for example in the case of glass walls and floors, differents results would be produced.

\subsection{VR Environment as Documentation}

Using the produced VR environment of the museum, several images can be rendered in different positions and views to produce high quality images with simulated lights, reflectivity, and textures. These images looked similar to the photographs which means it can accompany the conventional photo documentation of indoor environments such as for this museum.

\subsection{VR Environment as Visualization}

Visualizing of indoor environments is significant for various different purposes. For the purpose of advertisement and promotion, the VR environment can be used in the place of other publicity materials such as photos. In can also be used for demonstration, for example, to a client or a potential viewer or visitor.

\subsection{VR Environment as Immersive Experience}

There are different levels of immersion. Using the VR environment, several scenes can be rendered in sequence to produce a sequence of images that can be collated into a video for a semi-immersive video tour inside the museum. The virtual reality environment can be developed into a fully immersive experience by the use of game engines like Unity to provide the mechanics of movement and interaction.

\subsection{Versatility of the Virtual Reality Environment}

The product of the study which is a VR environment is much more versatile than other end-products like a video virtual tour, VR experience, and the like because it can be used to produce these end-products. Additionally it is also editable, if a new installation is provided in the museum, provided that the other installations are the same and at the same place, then the new installation could be modelled separately and added into the VR environment. Also, if installations are moved around, then these relocations can be reflected in the model by editing it.

\section{CONCLUSIONS}

In this study, photogrammetric modelling and 3D modelling were used together to model a VR environment of Bulwagan ng Dangal Museum found in the University of the Philippines-Diliman. The produced VR environment is versatile in the sense that it can used to produce other end-products which are useful for documentation, visualization, and immersive experience. Comparison to ground measurements show a minimum of $2.42 \%$ to maximum of $7 \%$ deviation from the actual and a root mean square error of $5.7 \mathrm{~cm}$. The survey for the comparison of photographs and panoramic images show that VR environments provide a good alternative to photographs and the actual physical interaction when a place is inaccessible.

Technology is ever advancing in capability. Immersive technology is no exception - it continues to develop at a rapid rate. Geospatial Science and mapping also continues to provide the world with better understanding through the use and study of spatial data. Combining the concepts of photogrammetry in modelling, 3D modelling, and virtual reality contributes to the ever expanding tool set of indoor GIS in visualizing data, informing users, and sharing the experience to other people.

\section{RECOMMENDATIONS}

There were distortions on the photogrammetric model because of reflective surfaces. The reflections were reduced by using a cheap CPL, a higher quality CPL may be used. In addition to this, a camera with higher specifications is preferred in conjunction with the higher quality CPL. This will produce higher quality images. As a consequence of this, images would take up more space which means that a computer with higher specifications is imperative. In general, higher quality equipment will yield better results at a faster pace. For the portions that cannot be modelled using photogrammetry, an artist specializing in 3D art can make better models for these. Overall, the researchers recommend better equipment. In the line of better equipment, a laser scanner can be used to get more accurate models and avoid having to create 3D models because of deficiencies in the photogrammetric model.

\section{REFERENCES}

3DFlow, $\quad$ n.d. $\quad 3 D F \quad$ Zephyr. https://www.3dflow.net/3df-zephyr-pro-3d-models-from-phot os/ (1 December 2018).

AutoDesk Website, n.d. Maya Overview. https://www.autodesk.com/products/maya/overview December 2018). 
Inzerillo, L., 2017. Smart SfM: SALINAS ARCHAEOlOGICAL MUSEUM. Int. Arch. Photogramm. Remote Sens. Spatial Inf. Sci., XLII-2/W5, 369-374. https://doi.org/10.5194/isprs-archives-XLII-2-W5-369-2017.

Lahti, M., Hellman, T., 2018. Photogrammetric 3D Modeling for Virtual Reality. https://www.researchgate.net/publication/327227913_PHOT OGRAMMETRIC_3D_MODELING_FOR_VIRTUÄL_REA LITY (1 December 2018).

MathWorks, n.d. Reconstructing an Image from Projection Data - MATLAB \& Simulink Example. https://www.mathworks.com/help/images/reconstructing-an-i mage-from-projection-data.html (1 December 2018).

Pezzuolo, A., Milani, V., Zhu, D., Guo, H., Guercini, S., Marinello, F., 2018. On-Barn Pig Weight Estimation Based on Body Measurements by Structure-from-Motion (SfM). Sensors 2018, 3603. https://doi.org/10.3390/s18113603.

Science Cinema VR, 2018. VR technology impact on information perception. https://medium.com/@AltairVR/vr-technology-impact-on-inf ormation-perception-a3463d591847 (1 December 2018).

Soler, F., Melero, F.J., Luzón, M.V., 2017. A complete 3D information system for cultural heritage documentation Elsevier Journal of Cultural Heritage, Volume 23, 49-57. https://doi.org/10.1016/j.culher.2016.09.008.

Virtual Reality Society, n.d. Applications of Virtual Reality. https://www.vrs.org.uk/virtual-reality-applications/ December 2018) 